\title{
Rauchen ist menschlich?
}

A us Anlass des Welt-Nichtrauchertages am 31. März dieses Jahres war viel zu lesen über das Rauchen. Weltweit rauchen laut Angaben der World Health Organisation (WHO) 1,1 Milliarden Menschen. In Deutschland rauchten im Jahr 2003 nach Mitteilungen des Robert-Koch-Instituts 28\% der Frauen (mit weiterhin kontinuierlich ansteigender Tendenz) und 37\% der Männer (fallende Tendenz) ab 18 Jahren - insgesamt immerhin 20 Millionen Menschen, wobei ein Drittel bis die Hälfte davon täglich mehr als 20 Zigaretten konsumieren. Das durchschnittliche Einstiegsalter für das Rauchen liegt in Deutschland bei erschreckenden 11,6 Lebensjahren und damit deutlich unter der gesetzlich erlaubten Grenze für das öffentliche Rauchen. Und die Konsequenz? Fast fünf Millionen Menschen sterben weltweit pro Jahr durch Zigarettenrauchen - das ist ein Mensch alle neun Sekunden!

Warum diese Horrorzahlen? Erinnern Sie sich doch an Ihre eigene Jugend. Man rauchte aus Neugier, aus Imponiergehabe, um als erwachsen zu gelten oder schlicht aus Protest. Daran hat sich bis heute nicht viel geändert, im Gegenteil: Die Attraktion des Rauchens nimmt besonders für Frauen offenkundig weiter zu. Zudem haben sich die Möglichkeiten, die vielfachen Verführungen zum Rauchen und die finanziellen Mittel dafür sogar drastisch erhöht. Allein in der Europäischen Union sind 1,1 Millionen Zigarettenautomaten aufgestellt, die rund um die Uhr Verfügbarkeit bescheren, oft genug in Gesellschaft von Automaten für Süßigkeiten, was Kinder und Jugendliche regelrecht anlockt. Und der Schritt zum dauerhaften Rauchen fällt umso leichter, je mehr die Umgebung durch rauchende Eltern, Lehrer, Film- oder Musikstars Einfluss nimmt.

Doch welche Eltern möchten sich eigentlich schon die Schuld einer Körperverletzung an ihren Kindern aufladen, wenn sie diese schon in der Schwangerschaft direkt oder durch Passivrauchen eventuell dauerhaft schädigen? Wie weit man einer Einsicht, zu der man fähig ist, nachgeben will, ist wohl auch eine Frage der Intelligenz. Menschen sind jedoch in vielen Dingen ohne weiteres bereit, sich und andere auch in größte Gefahr zu bringen, nur um im Augenblick etwas (manchmal nur scheinbar) Angenehmes zu erleben. Ist aber jemand, der so handelt, zu verurteilen? Wer ehrlich ist, muss zugeben, sich täg- lich vielfach so zu benehmen. Egoismus scheint eine sehr menschliche Eigenschaft zu sein. Aber genau hier kann die Prävention beginnen. Versteht man es, sich solche Situationen bewusst $\mathrm{zu}$ machen und versucht man diese dann zu vermeiden, wird man feststellen, dass dies immer öfter gelingen kann. Letztendlich ist das wie im Sport, zum Beispiel beim Golfen: Man wird immer besser, aber perfekt kann man - bis auf Ausnahmetalente nie werden. So wird es auch immer Raucher geben.

Erfreulicherweise wird im Bereich der Prävention schon viel getan: Die Tabakwerbung ist deutlichen Beschränkungen unterworfen, es gibt Nichtraucherflüge und Nichtraucherlokale oder zumindest rauchfreie Bereiche. Sogar auf Bahnhöfen und Flughäfen ist das Rauchen nur noch in bestimmten „Raucherzonen“ gestattet. Aber jenseits der hehren Appelle und Absichtsbekundungen müssen wir leider zur Kenntnis nehmen, dass bisher sämtliche Bemühungen, dem Rauchen als einem der bedeutendsten Gesundheitsrisiken Einhalt zu gebieten, fehlgeschlagen sind. Möglicherweise, weil wir es nicht verstehen, wirksam und überzeugend präventive Aspekte mit dem alterspezifischen Lebensstil der verführbaren und verführten Jugendlichen, der „aus Neugier Rauchenden“, zu verbinden. Hier ist Kreativität, vielleicht auch in der Werbebranche gefragt, denn die Jugendlichen brauchen Vorbilder. Damit wäre schon viel geholfen!

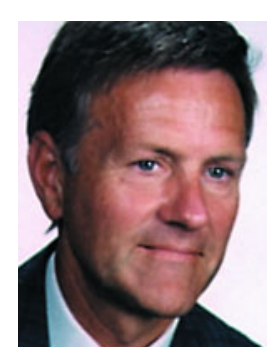

Prof. Dr. Burckart Stegemann, Hagen

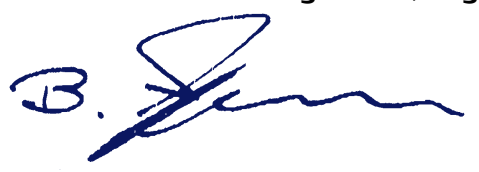

